\title{
The Study on Australian National Identity in Australian Gaming
}

\author{
Fuyuan Lei ${ }^{1} \mathrm{Ping}_{\mathrm{Yi}}{ }^{1 *}$ \\ ${ }^{1}$ School of Foreign Language, Chengdu University of Traditional Chinese Medicine, Chengdu, Sichuan 610072, China \\ *Corresponding author. Email: 904026750@qq.com
}

\begin{abstract}
Gaming or gambling has a crucial and distinctive place in the Australian culture. Many Australians are proud of their reputation as a nation of people who will "bet on two flies on the wall". This study attempts to explore the popularity of gaming in Australia and its relationship with the Australian national identity. Three representative elements in Australian national identity, egalitarianism, fatalism and mateship are discussed together with gaming, revealing a result that those cultural factors are all embodied in gaming. The study focuses on the cultural factors integrated in the gaming activities, using cultural elements to explain the significant social phenomenon.
\end{abstract}

Keywords: Australian gaming industry, gambling, Australian national identity

\section{INTRODUCTION}

Gaming has a crucial and distinctive place in the Australian culture. Since the first colonial settlement, gaming has been widespread throughout the country and "many Australians are proud of their reputation as a nation of people who will bet on two flies on the wall" [1]. From the first gaming among the convicts, to the leisure-seeking of the gold miners in the Gold Rush, and to the coin-flipping sweeping among the Anzac soldiers in WW I, gaming gradually developed into the significant part of the Australian culture throughout the ages, and had a close link to the Australian national identity. The traditional virtues like egalitarianism, fatalism, and mateship in Australian national identity all serve as evidences for the importance of gaming in the Australians' life. Generally speaking, the lure of easy money and the impulse of getting back the losses are the obvious explanations for gaming acts. However, in Australia, there is a profound cultural element contained under the wealth-chasing motivation. That is the relationship between gaming and Australian national identity.

\subsection{Australian National Identity}

What does it mean to be Australian? The famous description about Australian people was made by Russel Ward in his book The Australian Legend: "the typical Australian is a practical man...He is a great improviser...willing 'to have a go' at anything, ...gambles heavily and often, and drink deeply on occasion...he believes that Jack is not only as good as his master...fiercely independent person who hates officiousness and authority...yet he is very hospitable and, above all, will stick to his mates through thick and thin..."[2]. As a former colony of Britain, at the early stage of identity formation, in order to show the differences with English, Australians created the new image called "bushman", who displayed the respectable qualities like mateship, self-confidence, generosity and resourcefulness, better adapted to the Australian natural environment than English. After the establishment of the federation and during the WW I, the soldiers emerged as the national hero, becoming the new image of national identity. Till the modern time, when Australians thought life had already turned to urban and the bush-based image needed to be changed, the lifeguard as a national type was introduced. The general image of Australia keeps changing, but the most central and frequently mentioned elements embodied in are the same: egalitarianism, sports enthusiasm, fatalism, mateship, larrikinism, and anti-authoritarianism, etc.

\subsection{Australian Gaming Industry}

Australia is a country with the national passion for gaming. The first two sentences of John O'Hara's book A Mug's Game revealed a clear picture of how enthusiastic of Australians towards gaming. "Australian has long thought of themselves as a nation of gamblers-perhaps the world's greatest gamblers. The belief that typical Australians would bet on two flies crawling up a wall is even part of our folklore" [3]. According to a report issued by Dr. Paul Delfabbro and Dr. Amanda LeCouteur in the University of Adelaide, 2003, "Eighty percent of Australians and New Zealanders gamble at least once per year...per capita expenditure in Australia is almost $\$ 1000$ '[4]. The readers can understand the national passion towards gambling, not only from the statistics, but also from the cultural part. On the 2000 Sydney Olympic Game Opening Ceremony, the image of gamblers was clearly represented during the performance displaying the early settlers' life. Several actors, dressed as bush workers or gold diggers, squatting in a circle in front of a shabby timber cottage, concentrated on the dice-throwing. It was 
obvious that gaming had already been considered as an inalienable component of Austrian culture and history, which deserved the display on such a world-attentioned occasion. The Australian government benefits from the high tax income from gaming industry. Gaming taxation represents a significant share of state and territory governments' tax revenue. According to the reports from the Australian Bureau of Statistics, in 2006-07, state and territory governments collected around $\$ 4.8$ billion in revenue from gambling, representing 9.8 percent of state and territory taxation revenue [5]. In order to balance the potential harm the gaming may cause and the great income from the thriving industry, each state and territory government has specialized offices or departments to deal with the administration of gaming industry, and also has professional institutions for the remedy towards addicts in psychological perspective instead of incrimination

\section{GAMING IN NATIONAL IDENTITY}

Although the Australian national image experienced constant changes through the ages, the core features embodied inside are the same. The central values of Australian national identity are egalitarianism, sports enthusiasm, mateship, fatalism, larrikinism, and anti-authoritarianism. Just like Geoffrey Caldwell mentioned in his article The Gambling Australian, Australians have a predilection for gambling and the form of gambling is marked by heavy reliance on chance and so little on skill. "The reasons for such phonemes must be made to the nature of the Australian character and the value system-especially egalitarianism, mateship and fatalism"[6]. Therefore, in the following parts, the connection between gaming and the national identity will be explained in the three most related elements of Australian national identity.

\subsection{Egalitarianism in Gaming}

One of the most popular characters in Australian national identity is the belief of egalitarianism. Elaine Thompson points out in her book Fair Enough that "These beliefs include that Australia is a classless society because income and/or wealth are evenly distributed ... that the social styles of rich and poor are much the same...people were judged as individuals on their merit rather than on the basis of their class, status, wealth or reputation"[7]. Australia has forged egalitarianism in its founding era. The convict system ensured that the majority of the population was not the people in superior position. As the convicts, they were equal with each other. Later during the Gold Rush, the apparent accessibility of great wealth through luck deepened the belief in egalitarianism. The special history and developing circumstance cultivated the value of egalitarianism which has long been an important part of the way Australians have seen themselves. Actually gaming has provided a testimony for the Australian identity of being an equal society. The possibility of getting rich is equal to anyone who takes part in the games. Equality in gaming can be best illustrated by the Australian major horse racing, the Melbourne Cup, which is also one of the Australian national holidays. It enjoys the focus of the whole country, and is called a race that stops a nation. The first Melbourne Cup was run in 1861, having more than 150 years history till now. In 2019, more than 100,000 fans attend the Melbourne Cup in Flemington Racecourse, and millions of fans across Australia and around the world, who were not lucky enough to grab the limited tickets, enjoyed the race on TV or online, and gambled as well. Besides the statistics, the Australian national enthusiasm towards the Melbourne Cup can also be represented by the high-profile way of memorizing their legendary champion horse. Phar Lap is the name of the famous champion horse in Melbourne Cup, which won 37 of 51 races he entered in four years of his racing career. In the Melbourne Museum, Phar Lap's specimen is permanently displayed. And his heart has been preserved and displayed at the National Museum of Australia in Canberra.

The most important Australian national identity embodied in the Cup is the egalitarianism. The Melbourne Cup is a race for gamblers; a race which is based on uncertainty and the concept of equality of opportunity [8]. Everyone could bet on the game and has the possibility of getting rewards. In colonial time, the wealthy people regarded gambling pastime consumption. For the less wealthy gamblers, betting provided an opportunity for changing their station in life. Therefore, the horse racing was patronaged by colonial gentry as a mean of recreation and also as a method for keeping social order opened to the public, who took it as the possible way of getting rich. Hence this kind of betting was enjoyed by all the social classes with the betting "in both cash and kind, with wagers made in sawn timber, fat pigs, maize, butter, salted fish and snake-skin shoes"[9]. In the modern time, Melbourne Cup is a more egalitarian game than before. All the Australians enjoy the national holiday. Instead of taking fixed odds about a horse's chances, from a bookmaker, all bets were placed into a pool which was then divided between the successful inventors according to the number of units they invested on the winning horses. Australians took part in the game nationally, experiencing and strengthening the value of egalitarianism along with their gaming and betting. As the important feature in Australian national identity, egalitarianism finds its definition in the area of gaming. The pursuit for equality explains the Australian national passion toward gaming.

\subsection{Fatalism in Gaming}

In Australian definition, a sense of fatalism in Australian national character is a reflection of acceptance of chance, and an optimistic belief that something would come would come. Just like Horne described in his book The Lucky Country, Australians are quite satisfied about their current life, preferring "things move along more or less 
comfortably in their own direction", and "they try something to see if it works, pretty sure that it wills...almost a cult of optimistic improvisation..." [10]. Fatalism emerged from the unique history and natural environment in Australia. The life of early settlers was a fight against nature, seeking the survival by the blessing of the chance. The succession of droughts, floods and bush fires made early Australian believed that nature at times could not be tamed by man. Life was a big gamble. The bushmen and gold miners later also lived a similar life. It seems that "many Australians appear to accept that good and bad fortune can fall upon the individual whether he deserves it or not"'[11]. Australians have a fierce sense of fatalism, a tendency to attribute success to luck rather than goodness or ability.

Australians place their faith of luck in gaming, which seems quite seductive to think of themselves as lucky. The fact is that the non-skill gambling is preferred by Australians, like Two-up and poker machine, but some sophisticated betting games, which are popular in Europe and America, are not played frequently in Australia, even illegal in some states. Two-up, the unique Australian gambling contribution is the very game of fair and chance, which is a simple game of coin-tossing to bet on head or on tail with the wining possibility of 50-50. Given the knowledge of modern commercial gaming, this game would have little appeal for players and could not sustain a viable market. However, the fact is the simple game had thrived in Australia for over 200 years. In addition, in such popular gaming venues as the Crown Casino in Melbourne and the Star City Casino in Sydney, it can be found that the most popular game is the poker machine. Poker machines validate the coin or money inserted to play. The machine pays off based on patterns of symbols visible on the front of the machine when it stops. The only thing the gamblers need to do is inserting the coins and pressing the button, which is the game closely, relied on luck, similar to two-up. This kind of gaming dose not recognize skill, ability or status, but relies on the blessing by chance, in the behavior of button-pressing or the coin-throwing.

People rely on luck and accept what happens peacefully, believing that sometime they might recover the losses, or maybe not, since the orbit of fate is never to be known. The best way is to accept the loss and to try it again next time with an optimistic view that now the god of fortune might stand on a more favorable side.

\subsection{Mateship in Gaming}

Mateship is a significant part of the Australian national identity, which is an Australian cultural idiom that embodies equality, loyalty and friendship. "The central beliefs in mateship are the value of masculinity, resourcefulness, teamwork, loyalty to one's mates and the company of mates is preferable to the company of women" [12].

At the very beginning, with the first convict settlers in 1788 came the start of the male dominated society in Australia. From the beginning there was a gross imbalance in the gender proportion with male taking the dominant part. The other explanation for male dominance is the physically demanding living conditions. Furthermore, in order to meet the needs of survival, the first settlers had to stick together, depending on mutual aid to get them through. The mateship gradually took its shape in the brotherhood and the coexistence between people, especially males. The Gold Rush in the 1850 s contributed to the further development of Australian mateship. The gold miners' male-dominated situation and painstaking life were quite similar to the first settlers and bush workers, promoting the influence of the tradition of mateship. Mateship reached its highest levels during the war times, among the soldiers. Gammage said in his The Broken Years, a book about the Australians in the WWI that "mateship was a particular Australian virtue, a creed, almost a religion." [13]. In Australia, a "mate" is more than just a friend. It's a term that implies a sense of shared experience, mutual respect and unconditional assistance.

Although men may value mateship highly, in modern times, the opportunities for expressing mateship values are quite limited. Different from the convict age and bushman time, the nature no longer provides the common threat. What's more, in the peace age, there is no war for Australians to display the spirit of sharing life and death with the mates. The involvement with people is a little bit circumscribed. "This comparative lack of involvement both with persons and issues has reduced the areas in which Australians can experience excitement. Under these circumstances, many individuals have turned to sport and gambling for excitement satisfaction" [14]. From this aspect, mateship indirectly suggests a possible way for people to find excitement through leisure, like gaming. And what they prefer during their mate gathering also promotes the gambling behaviors. The value of mateship means men are expected to share interest in certain things and this becomes the basis of conversation. Australia is a country with a strong enthusiasm for sports. The result of the game and the sports heroes, and anything related to sports could be used as the conversational topics. Of course, gaming, the thing closely related to sports is the subject for discussion. The mate talk sometimes is self-glorifying which is also the part of showing the masculinity, especially about making money. In most of the pubs the mates gather, the poker machines are there waiting. After the fantasizing talk and by the stimulation of beer, some of them have the big possibility to try their luck to see whether the dream would come true. Mateship has indirectly promoted the development of gaming in Australia.

\section{CONCLUSION}

The Australian dominant ideology about the image of Australian national identity is seen as reflecting traditional virtues of egalitarianism, fatalism, and mateship. These elements all serve as evidences for the importance of gaming in the Australians' life. Gaming has long been one of the fabrics of the Australian national identity, in which 
[4] Delfabbro, P., LeCouteur, A. (2003). A Decade of Gambling Research in Australia and New Zealand (1992-2002): Implications for Policy, Regulation and Harm Minimization. Report for the Independent Gambling Authority of South Australia. University of Adelaide, Adelaide. pp 1.

[5] Australian Bureau of Statistics. (2008) Taxation Revenue, 2006-07. No. 5506.0. Canberra. pp 5

[6] [11] [14] Caldwell, G. (1974). The Gambling Australian. In: Donald E. E. (Eds.), Social Change in Australia: Readings in Sociology. Cheshire Publishing Pty Ltd, Melbourne. pp. 13-28.

[7] Thompson, E. (1994). Fair Enough: Egalitarianism in Australia. University of New South Wales Press, Sydney. pp introduction

[8] O'Hara, J. (1988). The Melbourne Cup and Two-up: Egalitarianism and Gambling. Sporting Traditions, 5(1): pp 61-76.

[9] Charlton, P. (1987). Two Flies Up a Wall: The Australian Passion for Gambling. Methuen Haynes Press, Sydney. pp 37.

[10] Horne, D. (1964). The Lucky Country: The Classic Study of Australia in the Sixties. Penguin Books, Ringwood, Victoria. pp 44.

[12] Dempsey, K. (1992). Mateship in Country Town. In: John, C. (Eds.), Intruders in the Bush. $2^{\text {nd }}$ Edition. Oxford University Press, Melbourne. pp 131.

[13] Gammage, B. (1990). The Broken Years: Australian Soldiers in the Great War. Illustrated Edition. Penguin Books, Ringwood, Victoria. pp 115.

[3] O'Hara, J. (1988). A Mug's Game: A History of Gaming and Betting in Australia. New South Wales University Press, Kensington. pp preface. 